3. Grass J. A. (2005), "Patient-controlled analgesia", Anesth Analg. 101(5 Suppl), p. S44-61.

4. Kulkarni Anita, et al (2018), "A comparative study of ropivacaine and bupivacaine with fentanyl for postoperative patient-controlled epidural analgesia after major abdominal oncosurgery". 1(2), p. 66-72.

5. Liu S. S., Allen H. W., Olsson G. L. (1998), "Patient-controlled epidural analgesia with bupivacaine and fentanyl on hospital wards: prospective experience with 1,030 surgical patients", Anesthesiology. 88(3), p. 688-95.

6. Eid Essam A., Alsaif Faisal A. (2007), Combined Epidural-General Anesthesia (CEGA) In Patients
Undergoing Pancreatic Surgery: Comparison Between Bupivacaine 0.125\% And 0.25\%.

7. Lv Bao-sheng, et al (2014), "Efficacy and safety of local anesthetics bupivacaine, ropivacaine and levobupivacaine in combination with sufentanil in epidural anesthesia for labor and delivery: a metaanalysis", Current Medical Research and Opinion. 30(11), p. 2279-2289.

8. Shantiraj Gunna, Kalyan Sankula (2018), "A study on evaluation of epidural levobupivacaine $0.125 \%$ and ropivacaine $0.125 \%$ with and without fentanyl for postoperative pain relief in abdominal surgeries", Journal of Evidence Based Medicine and Healthcare. 5, p. 2174-2179.

\title{
CÁC YẾU TỐ NGUY Cơ CỦA HUYẾT KHỐI TĨNH MACH SAU PHẪU THUÂ̂T TIỆT NIỆU: MộT NGHIÊN CỬU BÊ̂NH CHỨNG TỪ DỮ LIỆU BẢO HIỂM QUỐC GIA
}

\section{TÓM TẮT}

Nghiên cứu mô tả cắt ngang được tiến hành trên 145.479 người bệnh phẫu thuật tiết niệu từ 1/2017 đến 9/2018. Người bệnh được đánh giá điểm số nguy cơ trước phẫu thuât theo thang điểm Caprini hiêu chỉnh và được theo dõi trong khoảng thời gian 30 ngày sau phẫu thuật để xác định tỷ lệ huyết khối tĩnh mạch (HKTM). Phân tích hồi quy đa biến được thực hiển nhằm xác định các yếu tố nguy cơ liên quan đến HKTM sau phẫu thuật. Có 92 người được chẩn đoán mắc HKTM sau phẫu thuật trong vòng 30 ngày (chiếm tỉ lệ 0,06\%). Số người có điểm Caprini 3-4 điểm chiếm tỷ iệ nhiều nhất $(49,3 \%)$. Điểm Caprini càng cao thì nguy cơ mắc HKTM sau phẫu thuật tiết niệu càng tăng. Các yếu tố nguy cơ liên quạn có ý nghĩa $(p<0,001-0,01)$ đối với HKTM sau phẫu thuật tiết niệu bao gồm tuổi $>60$, tiền sử nhồi máu cơ tim, loét dạ dày, tiểu đường, ung thư, tăng huyết áp, suy tĩnh mạch, suy thận, tiền sử huyết khối, bệnh mạch máu ngoại vi. Các yếu tố này cần được đánh giá trước phấu thuật nhằm hỗ trợ ra quyết định dự phòng huyết khối tĩnh mach thích hợp trên lâm sàng.

Tư khóa: Huyết khối tĩnh mạch, yễu tố nguy cơ, phẫu thuật tiêt niệu

\section{SUMMARY \\ RISK FACTORS OF VENOUS THROMBOEMBOLISM AFTER UROLOGICAL}

\footnotetext{
${ }^{1}$ Trường Đại Học Y Hà Nội

${ }^{2}$ Bênh viện đại họ Y Hà Nôi

Chịu trách nhiệm chính: Bùi Mỹ Hạnh

Email: buimyhanh@hmu.edu.vn

Ngày nhận bài: 9.3.2021

Ngày phản biên khoa học: 27.4.2021

Ngày duyệt bài: 10.5.2021
}

Bùi Mỹ Hạnh ${ }^{1,2}$, Hoàng Long1,2

\section{SURGERY: A DISEASE STUDY FROM} NATIONAL INSURANCE DATA

A descriptive cross-sectional study was conducted on 145,479 urology patients from January 2017 to September 2018. The patient was assessed for the risk score before surgery according to the adjusted Caprini risk assessement model and was monitored for a period of 30 days after surgery to determine the rate of venous thromboembolism (HKTM). Multivariate regression analysis was performed to identify the risk factors associated with the postoperative venous thromboembolism. There were 92 people diagnosed as having venous thrombosis after surgery within 30 days (accounting for $0.06 \%$ ). The number of people with a Caprini score of 3-4 accounts for the highest proportion (49.3\%). The study showed that the higher the Capriniscore, the greater the risk of developing venous thromboembolism after urological surgery. The relevant risk factors $(p<0.001)$ for post-urinary surgery include age $>60$, history of myocardial infarction, gastric ulcer, diabetes, cancer, hypertension, varicose vein, renal failure, history of thrombosis, peripheral vascular disease. These factors need to be assessed prior to surgery in order to assist in making clinically appropriate decisions for venous thromboembolism prevention.

Key words: VTE, risk factors, urology patients.

\section{I. ĐẶT VẤN ĐỀ}

Huyết khối tĩnh mach là tình trang huyết khối làm tắc một phân hay toàn bộ tĩnh mạch sâu. Phân lớn HKTM không có triệu chứng lâm sàng, theo nghiên cứu của Pannucci $\mathrm{CJ}$ chỉ có $11 \%$ NB có triệu chứng lâm sàng [1]. Do vậy việc tâm soát và phòng ngừa bệnh này là cân thiết để phát hiện sớm, điều trị và ngăn chặn các biến chứng. Trong các thang điểm đang được sử dụng để phân tâng yếu tố nguy cơ HKTM, thang 
điểm Caprini được sử dụng phổ biến bởi tính đơn giản, dễ sử dụng với độ nhạy và độ đặc hiệu cao [2]. Tại Việt Nam phiên bản hiệu chỉnh của mô hình Caprini đã được áp dụng trong đánh giá nguy cơ ở người bệnh trải qua phẫu thuật chấn thương chỉnh hình, phẫu thuật mạch máu và phẫu thuật thần kinh [3]'[4]. Nghiên cứu này được thực hiện với mục tiêu:

1. Mô tả tỷ lệ HKTM sau phẫu thuật tiết niệu phân bố theo điểm Caprini hiệu chinh

2. Xác định các yếu tố nguy cơ HKTM ở người bênh trải qua thủ thuật - phẫu thuật tiết niệu theo mô hinh Caprini hiệu chinh

\section{II. ĐỐI TƯợNG VÀ PHƯƠNG PHÁP NGHIÊN CỨU}

2.1. Thời gian và nguồn số liệu nghiên cứu. Số liệu được lấy từ nguồn dữ liệu các bệnh viện có phẫu thuật trên cả nước có gửi chính thức lên cổng dữ liệu điện tử bảo hiểm quốc gia từ tháng 1 năm 2017 đến tháng 9 năm 2018. Chẩn đoán HKTM theo hướng dần của Hội lồng ngực Mỹ 2012. Chuẩn dữ liệu được xác thực đảm bảo theo yêu cầu kết nối mới được chấp nhận.

2.2. Thiết kế nghiên cứu. Nghiên cứu được tiến hành theo phương pháp thiết kế mô tả cắt ngang

2.3. Cỡ mẫu và chọn mẫu. Nghiên cứu lựa chọn phương pháp chọn mẫu thuận tiện

Tiêu chuẩn lứa chọn: Người bệnh trưởng thành (>18 tuổi) sau phẫu thuật tiết niệu và người bệnh được chẩn đoán xác định mắc HKTM

Tiêu chuẩn loại trừ: Người có HKTM tại thời điểm nhập viện hoặc trước phẫu thuật, người bệnh đang trong quá trình điều trị huyết khối, có chống chỉ định sử dụng thuốc chống đông vì bất kỳ lý do, hoặc sử dụng thuốc kháng tiểu cầu.

Cõ̃ mẫu thu được $n=145.479$ người bệnh thỏa mãn tiêu chuẩn và được đưa vào phân tích.

2.4. Định nghĩa và thời điểm thu thập các biến số

Định nghĩa biến số. Các biến số của nghiên cứu bao gồm (1) đặc điểm tuổi, giới tính, (2) Các yếu tố nguy cơ theo Thang điểm Caprini phiên bản 2013 với cách cho điểm từng yếu tố bao gồm:[2]

Các yếu tố nguy cơ 1 điểm: Từ 41 đến 60 tuổi; Đại phẫu hơn 45 phút trong 30 ngày trước phẫu thuật; Có kế hoạch tiểu phẫu (dưới 45 phút); thời gian phẫu thuật hiện tại >2 giờ; Giãn tĩnh mạch; Viêm loét đại tràng; Sưng chân (hiện tại); Thừa cân hoặc béo phì (BMI > 25); Nhồi máu cơ tim; Suy tim ứ huyết; Nhiễm khuẩn nặng (ví dụ viêm phổi); Bệnh phổi mạn tính (Hen, COPD); hạn chế vận động dưới 72 giờ; hút thuốc, đái tháo đường phụ thuộc insulin, đang dùng hóa trị, truyền máu, Hiện đảang dùng thuốc tránh thai hoặc liệu pháp hormon thay thễ (HRT); Có thai hoặc sinh con trong tháng trước; Tiền sử thai chết lưu, sẩy thai tự nhiên tái diễn $(>3)$, sinh non kèm nhiễm độc thai nghén.

Các yếu tố nguy cơ 2 điểm: Từ 61 đến 74 tuổi; Có bệnh ác tính trước đây hoặc hiện nay (trừ ung thư da không phải là u hắc tố); Có kế hoạch đại phẫu kéo dài hơn 45 phút (kể cả mổ nội soi ổ bụng và nội soi khớp); Bó bột hoặc đặt máng bột không tháo được để bất động chân trong tháng trước; Đặt catheter tĩnh mạch trung ương trong tháng trước; Nằm liệt giường trên 72 giờ.

Các yếu tố nguy cơ 3 điểm: Từ 75 tuổi trở lên; Tiền sử bản thân bị huyết khối; Tiền sử gia đình có bệnh huyết khối; Tiền sử cá nhân hoặc gia đình xét nghiệm máu dương tính cho thấy tăng nguy cơ đông máu

Các yếu tố nguy cơ 5 điểm: Mổ thay khớp kháng hoặc khớp gối; Gãy xương hông, xương chậu hay gãy chân; Đa chấn thương (do té ngã hay tai nạn giao thông); Tổn thương tủy sống gây liệt; đột quy.

Mồ hình đánh giá nguy cơ được hiệu chỉnh do các các biến số Tiền sử cá nhân hoặc gia đình xét nghiệm máu dương tính cho thây tăng nguy cơ đông máu. Các thông số xét nghiệm như yếu tố Leiden $V$, homocysteine huyết thanh, kháng thể kháng cardiolipin, prothrombin 20210A, chất chống đông lupus được loại khỏi mô hình thống nhất trong các nghiên cứu trước đây[3-5]

\section{Thời điểm thu thập biến số}

1. Trước phẫu thuật: Đánh giá các yễu tố nguy cơ cho từng người bệnh theo thang điểm Caprini

2. Sau phẫu thuât 30 ngày để xác đinh có/không mắc HKTM theo tiêu chuẩn chẩn đoán HKTM của "Khuyến cáo về chẩn đoán, điều trị và dự phòng thuyên tắc huyết khối tĩnh mạch" của Hội tim mạch quốc gia Viêt Nam năm 2016:

Chẩn đoán HKTM chi dưới: người bệnh có biểu hiện lâm sàng như sưng và đau ở một chân (thường là bắp chân), cảm giác đau nhức khi đứng hoăc đi bộ, ấm da ở vùng bị sưng, ban đỏ ở chân. Siêu âm Dupplex hoặc chụp tînh mạch chi dưới để chẩn đoán xác định có HKTM

Chẩn đoán tắc mạch phổi: người bệnh đột ngột xuất hiện khó thở không rõ nguyên nhân, đau ngực khi hít vào, ho ra máu và nhịp tim nhanh; Chẩn đoán xác định bằng chụp cắt lớp vi tính (CT) hoặc chụp động mạch phổi.

2.5. Xử lý và phân tích số liệu. Dữ liệu được trích xuất trực tiếp vào file cơ sở dữ liệu của STATA. Các thồng tin nhận dạng người bệnh 
như tên, địa chỉ, số điện thoại bị loai ra trước khi phân tích.

Chúng tôi sử dụng tần số và tỷ lệ để mô tả biến số định tính, trung bình và độ lệch chuẩn (ĐLC) để mô tả biến số định lượng. Kiểm định Chi-square và Fisher test được sử dụng để đánh giá sự khác biệt về nguy cơ mắc HKTM giữa các nhóm điểm Caprini. Mô hình hồi quy đa biến được sử dụng để xác định các yếu tố liên quan đến HKTM sau phẫu thuật tiết niệu. Kết quả được trình bày bằng tỷ số chênh $O R$ và khoảng tin cậy 95\% (KTC 95\%). Giá trị p < 0.05 được xem là có ý nghĩa thống kê. Tất cả các tính toán được thực hiện bằng phần mềm STATA 12.0.

2.6. Đạo đức nghiên cứu. Nghiên cứu đã được sự chấp thuận của Hội đồng đạo đức của Trường Đại học Y Hà Nội (số quyết định 67/HĐĐĐĐHYHN ngày 24/3/2017).

\section{KẾT QUẢ NGHIÊN CứU}

Bảng 1. Đăc điểm cơ bản của đôî tượng nghiên cứu ( $n=145.479)$

Bảng 2. Tỷ lệ măc HKTM theo nhóm điểm Caprini (n=145.479)

\begin{tabular}{|c|c|c|c|c|c|c|}
\hline Điểm Caprini & $\begin{array}{c}\text { Số' NB } \\
\text { phẩu thuật }\end{array}$ & $\begin{array}{c}\text { Số NB } \\
\text { mắc HKTM }\end{array}$ & $\begin{array}{c}\text { Tỷ lề mắc } \\
\text { HKTM (\%) }\end{array}$ & RR & $\mathbf{9 5 \% C I}$ & p \\
\hline 0-2 điếm & 40.178 & 7 & 0,02 & & & \\
\hline 3-4 điếm & 71.712 & 36 & 0,05 & 2,88 & $1,28-6,47$ & 0,0104 \\
\hline 5-6 điếm & 25.102 & 33 & 0,13 & 7,55 & $3,34-17,05$ & $<0,001$ \\
\hline 7-8 điếm & 4.422 & 6 & 0,14 & 7,79 & $2,62-23,16$ & $<0,001$ \\
\hline$>8$ điếm & 4.065 & 10 & 0,25 & 14,12 & $5,38-37,07$ & $<0,001$ \\
\hline Tống & 145.479 & 92 & 0,06 & & & \\
\hline
\end{tabular}

Nhận xét: Kết quả Bảng 2 cho thấy có 92 người bệnh được chẩn đoán mắc HKTM sau phẫu thuật (chiếm tỷ lệ $0,06 \%$ ). Tỷ lệ này tăng dần theo điểm số Caprini và cao nhất là ở nhóm có Caprini $>8$ điểm $(R R=14,12)$. Sự khác biêtt có ý nghĩa thống kê với $p<0,001$.

Bảng 3. Yếu tố nguy cơ mằc HKTM sau phẩu thuật tiết niệu $(n=145.479)$

\begin{tabular}{|c|c|c|c|c|c|c|}
\hline & Đặc điểm & HKTM & Không mắc HKTM & $\mathbf{R R}$ & $95 \%$ CI & $\mathbf{p}$ \\
\hline Giới & Nam & 63 & 104127 & & & \\
\hline Glol & Nữ & 29 & 41260 & 1,16 & $0,75-1,8$ & 0,50 \\
\hline & $18-40$ & 11 & 31821 & & & \\
\hline Tuổi & $41-60$ & 23 & 58435 & 1,14 & $0,06-2,33$ & 0,72 \\
\hline 1001 & $61-74$ & 37 & 35596 & 3,01 & $1,53-5,89$ & $<0,01$ \\
\hline & $>74$ & 21 & 19535 & 3,11 & $1,5-6,44$ & $<0,01$ \\
\hline & Nhồi máu cơ tim & 2 & 507 & 6,33 & $1,56-25,63$ & 0,01 \\
\hline & Xơ vữa động mạch & 1 & 68 & 11,23 & $0,70-179,09$ & 0,09 \\
\hline & Mạch máu não & 10 & 8887 & 1,8 & $0,97-3,61$ & 0,04 \\
\hline & Bất động > 72 giờ & 1 & 352 & 2,22 & $0,14-35,63$ & 0,57 \\
\hline & Hô hấp mạn tính & 5 & 4827 & 1,67 & $0,68-4,12$ & 0,26 \\
\hline & Loét dạ dày & 29 & 22045 & 2,57 & $1,66-3,99$ & $<0,01$ \\
\hline măc & Suy tim & 2 & 2910 & 1,09 & $0,27-4,42$ & 0,906 \\
\hline & Tiếu đường & 5 & 581 & 23,16 & $3,27-55,06$ & $<0,01$ \\
\hline & COPD & 0 & 879 & 0,89 & $0,06-14,30$ & 0,93 \\
\hline & Ung thư & 20 & 13456 & 2,72 & $1,66-4,46$ & $<0,01$ \\
\hline & Tăng huyết áp & 37 & 34154 & 2,19 & $1,44-3,32$ & $<0,01$ \\
\hline & Suy tĩnh mạch & 14 & 571 & 44,46 & $25,32-79,62$ & $<0,01$ \\
\hline
\end{tabular}


TẠP CHÍ Y HỌC VIẸT NAM TẬP 502 - THÁNG 5 - SÓ 2 - 2021

\begin{tabular}{|c|c|c|c|c|c|c|}
\hline & Suy hô hấp & 0 & 275 & 2,84 & $0,18-45,69$ & 0,46 \\
\cline { 2 - 7 } & Suy thận & 10 & 7505 & 2,24 & $1,16-4,31$ & 0,01 \\
\cline { 2 - 7 } & Mạch máu ngoại vi & 3 & 376 & 12,91 & $4,10-40,60$ & $<0,01$ \\
\cline { 2 - 7 } Tiền huyết khối & 16 & 1051 & 25,63 & $5,71-46,79$ & $<0,01$ \\
\cline { 2 - 7 } & Bệnh gan & 7 & 5151 & 2,24 & $1,04-4,84$ & 0,04 \\
\hline
\end{tabular}

Nhận xét: Kết quả bảng 3 cho thấy nguy cơ HKTM sau phẫu thuật tiết niệu là tuối $>60$, nhồi máu cở tim, loét dạ dày, tiểu đường, ung thư, tăng huyết áp, suy tĩnh mạch, suy thận, mạch máu ngoại vi, tiền sử huyết khối, với mức liên quan có ý nghĩa thống kê $(p<0,001)$.

\section{BÀN LUẬN}

Các báo cáo trước đây đã chỉ ra rằng huyết khối tĩnh mạch (HKTM) sau phẫu thuật tiết niệu là một trong những biến chứng có tỷ lệ thấp nhưng vẫn được coi là một trong những nguyên nhân chủ yếu làm tăng thời gian nằm viện, gánh nặng chi phí và tử vong nếu không được dự phòng hay phát hiện kịp thời. Trong nghiên cứu của chúng tôi, tỷ lệ mắc HKTM ở người bệnh sau phẫu thuật tiết niệu là $0,06 \%$. Kết quả này thấp hơn so với nghiên cứu của tác giả Scarpa trên những người bệnh sau phẫu thuật tiết niệu là $0,87 \%$, trong đó có 3 ca tử vong [6]. Sự khác biệt về kết quả này có thể do sự khác nhau trong cách lựa chọn quần thể nghiên cứu, thiết kế nghiên cứu, phương pháp thu thập số liệu, tỷ lệ, thời gian và kiểu điêuu trị dự phòng kháng đông.

Kết quả cho thấy tỷ lệ mắc HKTM tăng dần theo số điểm Caprini: điểm số càng cao thì nguy cơ mắc HKTM sau phẫu thuật tiết niệu càng cao, trong đó rõ rệt nhất là ở nhóm điểm Caprini $>8$ với nguy cơ tương đối (RR) là 14,1 với $p<0,001$ (bảng 2). Kết quả này phù hợp với nghiên cứu của chúng tôi về đánh giá nguy cơ HKTM trên 2,7 triệu người bệnh trải qua các thủ thuật phẫu thuật khác nhau qua mô hình Caprini hiêu chỉnh với tỷ lệ HKTM phân bố theo nhóm điểm Caprini tăng tỷ lệ thuận từ $0,04-0,45 \%$ [5]. Tương tự, nghiên cứu tác giả Kanchan đánh giá nguy cơ HKTM ở người bệnh phẫu thuật bằng sử dụng hệ thống tính điểm Caprini hiệu chỉnh cho thấy nguy cơ và tỷ lệ mắc HKTM tăng mạnh theo nhóm điểm 3-4 đến nhóm điểm >8 [7].

Việc phân loại người bệnh trong nhóm nguy cơ cao nhất (điểm Caprini $>5$ ) là vô cùng cần thiết để nhận biết chính xác các trường hợp cần phải được tăng cường việc điêu trị dự phòng huyết khối nhất. Tuy nhiên kết quả này chưa thể hiện mức điểm $>5$ là điểm số nguy cơ cao nhất để có thể ra quyết định dự phòng an toàn. Bên cạnh đó, tác giả Pannucci thực hiện nghiên cứu tính hợp lệ của thang điểm Caprini hiệu chỉnh và cho thấy rằng, so với người bệnh có điểm Caprini 3-4, người bệnh có điểm 7-8 hoặc cao hơn có khả năng cao bị mắc HKTM với OR lần lượt là 4,5 và 20,9 [1]. Các kết quả đã cho thấy việc sử dụng thang điểm Caprini hiệu chỉnh trong phân loại nhóm người bệnh có nguy cơ cao nhất là hữu ích trong việc đánh giá chính xác mức độ nguy cơ HKTM, giúp các nhà lâm sàng đưa ra các biện pháp dự phòng huyết khối phù hợp hơn. So với các nghiên cứu trước của chúng tôi về tính hợp lệ của thang điểm Caprini hiệu chỉnh ở những người bệnh phẫu thuật chấn thương và phẫu thuật mạch máu $[3,4]$ nghiên cứu trên người bệnh phẩu thuật tiết niệu cũng cho thây sự tương đồng về sự gia tăng nguy cơ và tỷ lệ mắc HKTM sau phẫu thuật theo điểm số Caprini.

Bảng 3 cho thấy mối liên quan của sự khởi phát HKTM sau phẩu thuật tiết niệu với các yếu tố nguy cơ như tuổi $>60$, nhồi máu cơ tim, loét dạ dày, tiểu đường, ung thư, tăng huyết áp, suy tĩnh mạch, suy thận, mạch máu ngoại vi, tiền sử huyết khối. Kết quả này phù hợp với nghiên cứu của tác giả Petralia và Kakkar về tình trạng dự phòng huyết khối ở người bệnh phẫu thuật tổng quát có các yếu tố nguy cơ như tuổi, ung thư và đang điều trị ung thư, tiền sử huyết khối, suy tĩnh mạch, và sử dụng estrogen [8]. Kết quả nghiên cứu của chúng tôi cho thấy người có tiền sử loét dạ dày có nguy cơ HKTM khá cao. Dù đây không phải là thành tố của thang điểm Carpini nhưng có thể vì lý do sợ chảy máu dạ dày sau phẫu thuật cũng như tác dụng không mong muốn của thuốc chống đông nên đã trở thành yếu tố gây nguy cơ huyết khối cao hơn rõ rệt. Bên cạnh đó, sự khác nhau của các yếu tố nguy cơ HKTM theo từng loại phẫu thuật chính là điểm đáng lưu ý cho các bác sỹ trong việc chỉ định điêu trị dự phòng huyết khối và theo dõi trong thực tế lâm sàng.

\section{KẾT LUẦN}

Tỷ lệ mắc của HKTM sau phẫu thuật tiết niệu là $0,06 \%$. Điểm số nguy cơ tương đối tăng theo các nhóm điểm Caprini $3-4,5-6,7-8$ và $>8$ lần lượt là 2,$88 ; 7,55 ; 7,79$ và 14,12 . Các yếu tố nguy cơ HKTM sau phẫu thuật tiết niệu được ghi nhâan là tuổi $>60$, nhồi máu cơ tim, loét dạ dày, tiểu đường, ung thư, tăng huyết áp, suy tĩnh mạch, suy thận, mạch máu ngoại vi, tiền sử huyết khối $(p<0,001)$. 


\section{TÀI LIÊU THAM KHẢO}

1. Pannucci CJ, Bailey SH, Dreszer G và các cộng sứ. (2011), "Validation of the Caprini risk assessment model in plastic and reconstructive surgery patient", J Am Coll Surg, 212(1), 105-12.

2. Caprini JA (2010), "Risk assessment as a guide for the prevention of the many faces of venous thromboembolism", The American Journal of Surgery, 199(1), 3-10.

3. Bùi Mỹ Hanh, Đào Xuân Thành, Nguyễn Hoàng Hiệp và các cộng sự. (2019), "Khảo sát một số yếu tố nguy cơ của hưyêt khối tî́nh mạch ở người bệnh sau phâuu thuật chấn thương chỉnh hình", Nghiên cứu y học, 121(5), 81-88.

4. Bùi Mỹ Hanh, Đoàn Quốc Hưng và Hoàng Thi Hồng Xuyến (2019), "Ứng dụng thang điểm caprini hiêu chỉnh trong đánh giá nguy cơ huyết khối tĩnh mạch trên người bệnh phẩu thuật mạch máu",
Nghiên cứu y học, 122(6).

5. Bùi Mỹ Hanh, Dương Tuấn Đức và Trân Tiến Hưng và cộng sự (2019), "Chi phí điều trị trự̛́c tiếp biến chứng huyết khối tĩnh mạch sau phẩu thuât 30 ngày ", Nghiên cứu Y hocc, 123(7), 86-93.

6. Scarpa RM, Carrieri G, Gussoni G va các cộng sư. (2007), "Clinically overt venous thromboembolism after urologic cancer surgery: results from the @RISTOS Study", Eur Urol, 51, 130-135.

7. Kanchan B, Anitha M, Mohsina S và các công sư. (2016), "Assessing the risk for development of Venous Thromboembolism (VTE) in surgical patients using Adapted Caprini scoring system", Int J Surg, 30, 68-73.

8. Petralia GA và Kakkar AK (2008), "Venous thromboembolism prophylaxis for the general surgery patient: where do we stand?", Semin Respir Crit Care Med, 29, 83-89.

\section{KẾT QUẢ ĐIỀU TRI VIÊM PHỔI NĂNG Ở TRẺ TỪ 2 THÁNG ĐẾN 5 TUỔI TẠI BỆNH VIỆN BÊ̂NH NHIỆT ĐỚI THÀNH PHỐ HỒ CHÍ MINH}

Ngô Minh Xuân*

\section{TÓM TẮT}

Muc tiêu: Xác đinh tỉ lê các đăc điểm điều trị và kết quả điều trị; Xác định các yếu tố liên quan đến kết quả điều trị viêm phổi năng ở trẻ từ 2 tháng đến 5 tuổi tại Bệnh viện Bệnh Nhiệt Đới Thành phố Hồ Chí Minh. Đối tượng, phương pháp: Bệnh nhi từ 2 đến 59 tháng được chẩn đoán viêm phổi cộng đồng nặng và điều trị tại khoa Nhi $D$ (khoa hô hấp) Bệnh viện Bệnh Nhiệt Đới từ tháng 10/2019 đến tháng 10/ 2020. Đánh giá kết quả điều trị sau 48 giờ nhập viện. Kết quả: Kháng sinh ban đâu: Ceftriaxone $92,8 \%$, Cefoperazon/ Sulbactam (6\%), phối hợp Ceftriaxone + Vancomycin (1,2\%). Diến tiến đáp ứng kháng sinh ban đầu: đáp ứng 95,2\%. không đáp ứng 4,8\%, phải thêm hoăc đổi kháng sinh. Kết quả điều trị: Thành công $86,9 \%$, thất bại $13,1 \%$. Các yếu tố liên quan đến kết quả điều tri: Trẻ có bênh nền có tỉ lê điều trị thành công thấp hơn nhóm khổng có bệnh nền $(O R=17,4$, $\mathrm{P}<0,05)$. Trẻ có tiền căn tiếp xúc với người ho/ sổ mũi trong tuần qua có tỉ lệ điều trị thành công thấp hơn nhóm không tiếp xúc $(O R=9, P<0,05)$. Kết luân: Viêm phổi trẻ em cần chẩn đoán và điêuu trị sớm nhằm giảm tỉ lệ biến chứng và tử vong.

Tư khoá: viêm phổi nặng, kháng sinh, biến chứng

\section{SUMMARY \\ TREATMENT RESULTS OF SEVERE PNEUMONIA IN CHILDREN AGED 2}

\footnotetext{
*Trường Đại học Y Phạm Ngọc Thạch, Tp Hồ Chí Minh Chịu trách nhiệm chính: Ngô Minh Xuân

Email: xuanlien62@pnt.edu.vn

Ngày nhận bài: 10.3.2021

Ngày phản biên khoa học: 28.4.2021

Ngày duyệt bài: 11.5.2021
}

\section{MONTHS TO 5 YEARS AT THE HO CHI MINH CITY TROPICAL DISEASES HOSPITAL}

Objectives: To review the treatment characteristics and treatment results of severe pneumonia in children aged 2 months to 5 years at the Ho Chi Minh city Tropical Diseases Hospital; and explore the related factors to the outcomes. Subjects and methods: Pediatric patients aged 2 to 59 months were diagnosed with severe communityacquired pneumonia and treated at Pediatrics Department D (respiratory department) of Ho Chi Minh city Tropical Diseases Hospital from October 2019 to October 2020. Evaluation of treatment results after 48 hours of admission. Results: Initial antibiotics: Ceftriaxone 92.8\%, Cefoperazone/ Sulbactam $(6 \%)$, combination of Ceftriaxone + Vancomycin $(1.2 \%)$. Progression of initial antibiotic response: $95.2 \%$ response. do not respond $4.8 \%$, must add or change antibiotics. Treatment results: Success $86.9 \%$, failure $13.1 \%$. Factors related to treatment outcome: Children with underlying disease have a lower success rate of treatment than the group without underlying disease $(\mathrm{OR}=17.4, \mathrm{P}<0.05)$. Children with a history of contact with a cough/runny nose in the past week had a lower success rate than the non-contact group $(\mathrm{OR}=9, \mathrm{P}<0.05)$. Conclusion: Pediatric pneumonia requires early diagnosis and treatment to reduce morbidity and mortality.

Keywords: severe pneumonia, antibiotics, complications.

\section{I. ĐĂT VẤN ĐỀ}

Viêm phổi là một trong những nguyên nhân hàng đầu gây tử vong ở trẻ 1-59 tháng. Năm 2015 có 920.136 trẻ em dưới 5 tuổi tử vong vì viêm phổi, chiếm $16 \%$ tổng số ca tử vong của 